EXCLUSIVE TO VITAL!

This article is adapted from a chapter of the upcoming second edition of Advanced dental nursing edited by Robert Ireland and published by Wiley Blackwell (Publication date: Spring 2010)

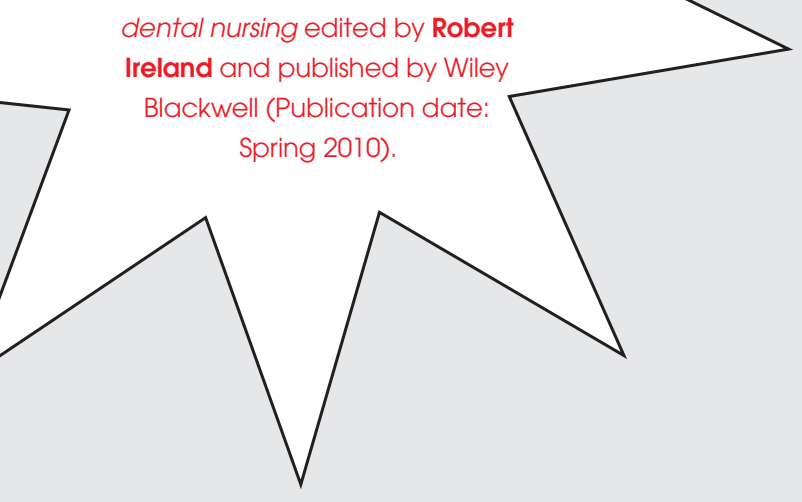

\section{ADVANCED DENTAL NURSING SERIES}

COMMUNICATION

CLINICAL GOVERNANCE AND RESEARCH

ORAL HEALTH EDUCATION

SPECIAL CARE DENTISTRY

SEDATION

ORTHODONTIC NURSING

IMPLANT NURSING

\title{
Can you help your
} patients through better communication?

By Mike Wanless,

Clinical Director, Greater Manchester School for Dental Care Professionals.

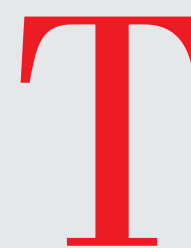

here are many aspects to consider when communicating with individuals or groups. In oral health education much communication involves face-to-face contact with an individual, a family unit or a group. Face-toface communication is a two-way process in which all participants transmit information about what they know and feel. If you preach at the patient or try to deliver standardised messages to them without really understanding their concerns, it is unlikely to be effective in bringing about an improvement in oral health. Effective communication involves being aware of the other person. It also involves what we are saying, how we are saying it, and how it is being interpreted by other people. Everyone makes judgements about the other person with whom they are communicating and there are skills which you can use to convey messages and to recognise how they are being interpreted.

Research has shown that we rapidly make judgements about the other person with whom we are communicating. This applies whether we are talking, listening or observing. The judgements made can help or hinder communication. It has been shown that when an individual makes a judgement on what sort of person is communicating with them or on how that person feels, the decision is based on a combination of factors. These can be classified as verbal, paralinguistics and non-verbal communication. Verbal communication relates to what the person says. Paralinguistics relates to how they say it and includes voice tone and volume, speed of speech and the uhms and ahs they say. Non-verbal communication includes gestures, facial expression, eye contact, body language and clothes.

Research has indicated that value judgements on the person communicating with us are based on these three factors in the following percentages:

- Verbal-7\%

- Paralinguistics - 38\%

- Non-verbal-55\%.

These figures are only approximate but indicate the relevance of the adage 'It isn't what you say, but the way that you say it'. Further they show that non-verbal communication is the most important factor in assessing the person with whom we are communicating. You should therefore be aware of the signals 


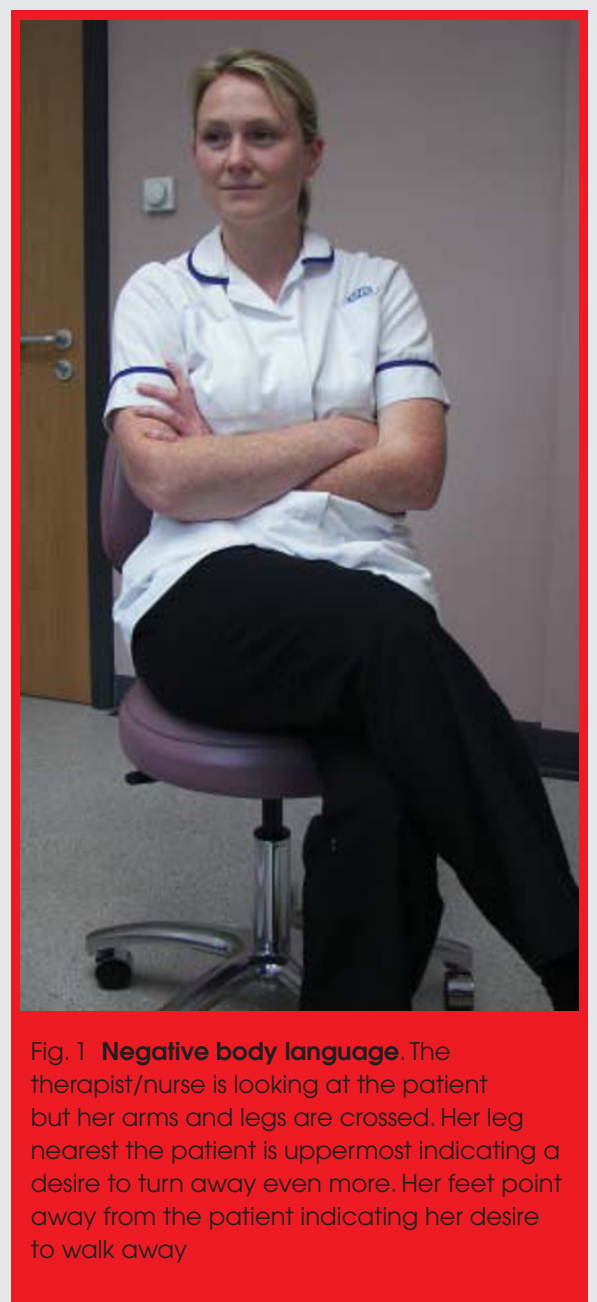

they are transmitting non-verbally and those of the patient or group with whom they are communicating

If you are to address the needs of your patients the most important communication skill is listening. Unless the patient's needs can

\section{'For effective}

\section{demonstration of} listening skills the oral health educator should face the client squarely.'

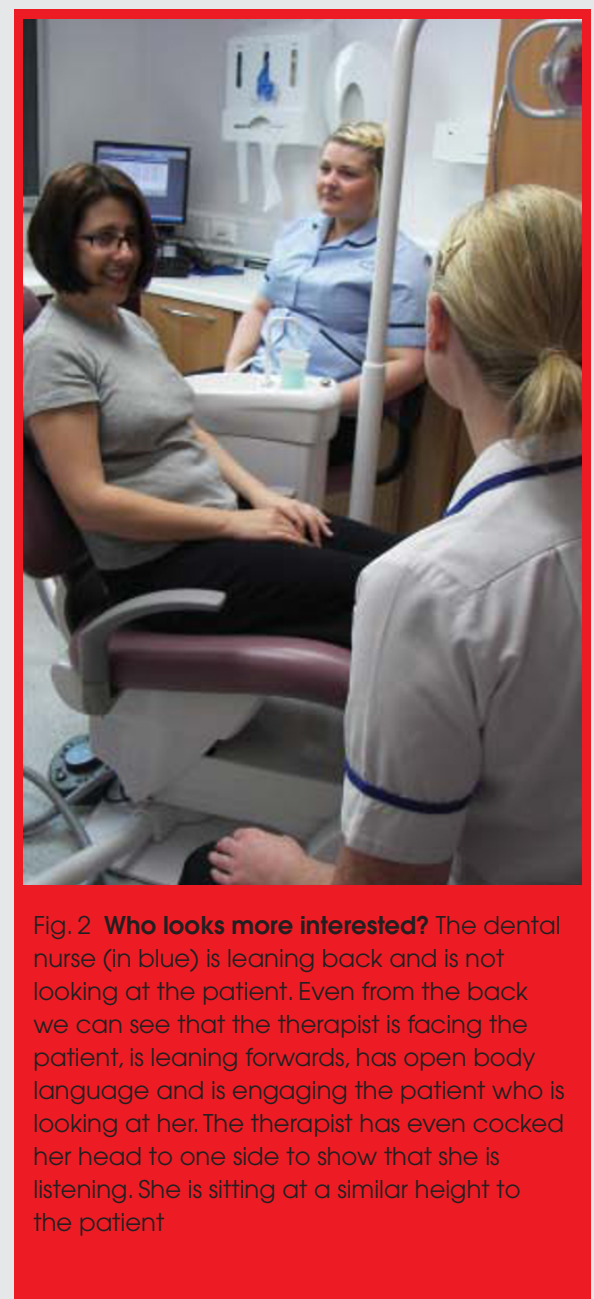

be identified they cannot be met. It is important that you should both listen and show that he or she is listening. Active listening is a term used to indicate the skills that show one is listening. It involves appropriate verbal responses, but again paralinguistics and nonverbal communication are the more important features. The acronym SOLER is useful for the non-verbal demonstration of listening:

- Square

- Open

- Leaning

- Eye contact

- Relaxed

Square. For effective demonstration of listening skills the oral health educator should face the client squarely. Otherwise he or she might seem uninterested. If the patient is in the dental chair this does not mean that you have to sit at their feet, but sit facing them. It is worth remembering that the dental chair is a very scary place for some people and that panic does not aid memory.

Open. Open body position involves avoiding crossing arms and legs, as these are often interpreted as a defensive or shutting out action (Fig. 1).

Leaning. A slight forward lean indicates an eagerness to hear more, but if overdone can be seen as aggressive (Fig. 2).

Eye contact. When listening most people maintain eye contact for around $70 \%$ of the time and this encourages speakers to continue. It also shows your interest in them and is important in developing rapport.

Relaxed. A relaxed posture is important, as otherwise the communication will seem very artificial (Fig. 3).

You should also be aware of the effects of height and distance. Height is often associated with power. Patients may feel vulnerable if they have to look up at the person with whom they are communicating. For discussion as equals, both parties should be at an equal height (Fig. 4). Shy people may feel more confident speaking if the other person is lower than they are. All people have an area of personal space and feel threatened if a person with whom they are not intimate invades it. You should look for non-verbal clues to check they are not too close to the person they are trying to help. They should also look for similar clues to indicate that they are not too distant. If they are too far away, communication will be lacking any sense of working together and is not likely to be effective. Some people need more personal space than others. City dwellers are used to having people around them and will tolerate the close proximity of strangers better than country dwellers. The appropriate distance varies with their relationship to the other person with whom they

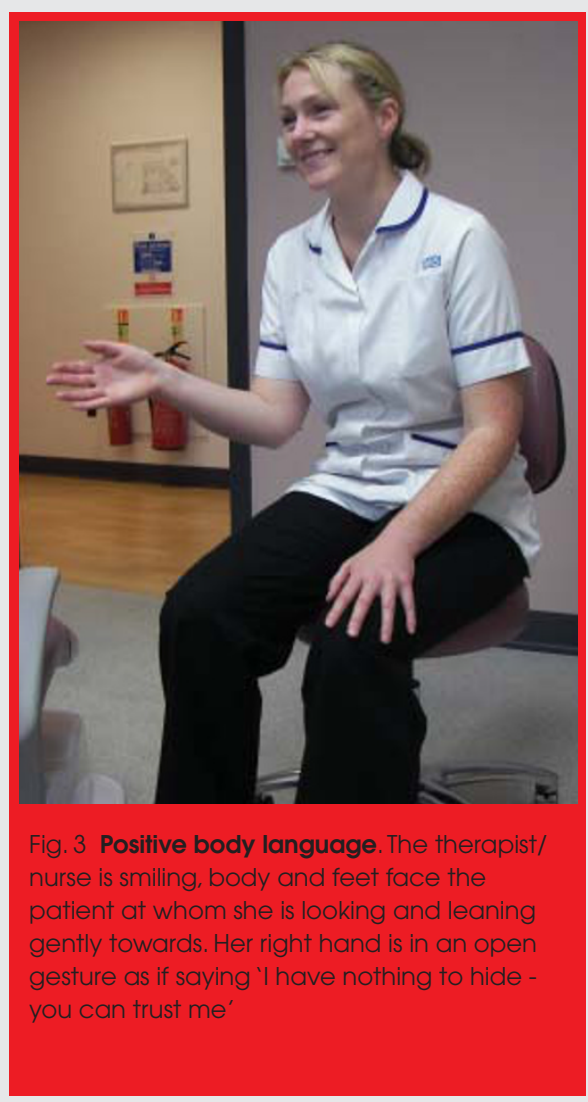


are communicating. The closer the relationship to the other person, the closer they will be tolerated. Because of the individual nature of personal space it is worth asking if the patient is comfortable with the standing or seating arrangements and moving either nearer or further apart if they are not.

\section{Barriers to communication}

It is also useful to be aware of potential barriers, which may impact on the delivery of oral health education/promotion. Social and cultural barriers include:

- Ethnic/cultural and religious beliefs

- Socioeconomic groups

- Family values.

All of the aforementioned must be carefully considered in order not to offend or set objectives, which perhaps cannot be achieved due to pressures outside the control of the individual or group.

It may be the case that an individual may not wish to or cannot communicate because of learning disabilities or may be too busy or preoccupied and does not see oral health as important in his or her list of priorities. On some occasions negative communication may be influenced by:

- A bad past experience of dental treatment

- The patient thinking the oral health educator will pass judgement or criticise

- The patient thinking they know it all in relation to the advice being offered

\section{'Because of}

\section{the individual}

nature of

personal space it

is worth asking

if the patient is

comfortable with

the standing

or seating

arrangements

and moving

either nearer or

\section{further apart if} they are not.'

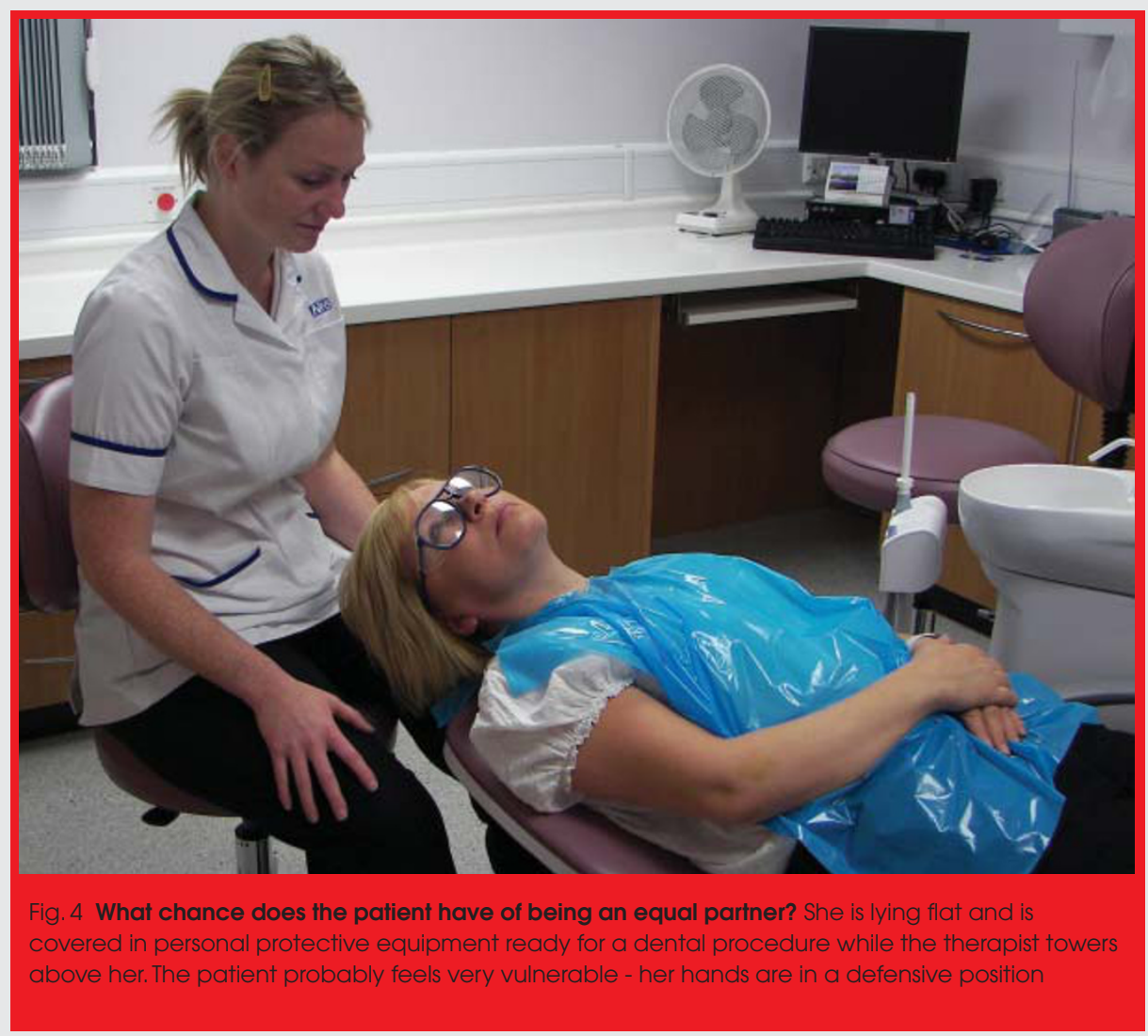

- Objectives being set too high. A patient may feel they cannot comply

- Financial constraints. These will have an impact on the availability to purchase toothbrushes, toothpaste etc

- Social constraints which relate to lifestyle. A patient may not want to give up sweets as they are used as a comforter or bribe with children.

Limited understanding or memory, poor English and the use of jargon or dental terminology will all have an influence on communication. Therefore knowing the target group will assist in the correct information being delivered in the most appropriate way. Reinforcement of messages will reduce the possibility of information fade. It is important that contradictory messages between other health workers offering conflicting advice or 'experts' changing their minds is minimised to enable the individual delivering or receiving information to have confidence and credibility. It is also important to be realistic and acknowledge that some deeply held beliefs may be contrary to current oral health education messages and extremely difficult to change.

\section{Ways to improve communication}

Communication is a two-way process which involves listening as well as talking. By using some simple techniques it is possible to improve the interaction between individuals or groups. The following need to be considered.

\section{Respect}

By identifying the patient's needs, expectations and involving them in decision making it is more likely that a positive outcome will be achieved. Showing that we have remembered things about them which are not directly related to their oral care help demonstrate respect and interest.

\section{Listening skills}

Listening to patients is essential for an oral health educator to be able to help them. Patients' descriptions are not always articulate or clear, particularly if they are feeling upset or scared. Try to pay attention to their feelings as well as their words. Nervous patients may be reluctant to speak so giving them extra time can help them plan what to say. They may be asking themselves 'Is this the best time to say how I feel?' Hippocrates said 'Listen to the words and the silence'.

\section{Questioning skills}

Patients can be helped to talk by adopting a careful questioning technique. The following 
are examples of some of the different types of questions which may be used, although some are best avoided:

\section{Closed questions}

These invite a short response usually 'yes' or 'no'. Questions such as 'Do you like visiting the dentist?, 'Do you know what plaque is?' or 'Are you going to do this now or later' are examples of closed questions. They fail to open up the conversation and allow the patient to give a reply without necessarily having given it much or any thought. Closed questions should be avoided. They can, however, be used to clarify what the patient has said but only give limited information.

\section{Open questions}

These provide no guidance to the patient as to what might be the correct answer and cannot be answered by either 'yes' or 'no'. They require the patient to give some thought to the response. Examples are: 'What type of toothbrush do you use?', 'How often do you attend the dentist?', 'What is plaque?'.

\section{Leading questions}

These give the patient an indication of the answer which is expected. 'Surely you don't brush your teeth only once a day?' or 'You don't have more than one fizzy drink a day do you?' are examples of leading questions because they give clues as to the answer that the questioner wishes to hear. The answers will therefore not necessarily be truthful.

\section{Multiple questions}

'Do you brush and floss your teeth?' is a multiple question. If the person questioned answers 'Yes', it would be impossible to determine whether the reply is yes to brushing, flossing or both. This type of question only serves to confuse everyone.

\section{Offensive questions}

It is all too easy to antagonise a patient by using an ill-conceived question. Saying to an overweight person 'Do you eat a lot of chips or doughnuts?' is likely to be interpreted as being offensive ... even if it is true.

\section{Ambiguous questions}

'Do you go to the dentist for regular check ups?' is an ambiguous question since 'regular' to one patient might be once every six months whereas to another it might mean a visit every five years.

\section{Eliciting information without questions}

If you ask too many questions it might seem to the patient more like an interrogation than a

\section{'A comfortable,} non-clinical setting in which the seats are deliberately positioned at the same height to prevent a non-threatening approach is desirable.'

conversation to which they want to contribute. There are useful alternatives to asking questions to find out about your patients. One is to say 'Tell me about.......This encourages patients to express themselves in their own words. This can give you a good indication of what is important to them. Repeating back to them what they have just said, like an echo, will usually enable them to tell you more or to justify their comments.

Encouragement should be offered, as this in turn will enable the patient to feel positive about changes that are suggested.

Other aspects of non-verbal communication should also be considered when interacting with patients, eg:

- Physical appearance, ie uniform or casual clothes

- Facial expression - welcoming smile

- Hand and head movements acknowledges responses

- Non-verbal behaviour - yawning or clock watching indicate a lack of interest!

The environment in which oral health advice is offered can have an impact on the patient's receptiveness to advice. A comfortable, non-clinical setting in which the seats are deliberately positioned at the same height to prevent a non-threatening approach is desirable. This format will enable the patient to feel more comfortable.
Language should also be carefully considered as follows:

- Tailor messages to the needs of the individual

- Talk at the same level

- If there are communication problems, speak clearly and simply

- Do not use jargon

- Use a logical sequence when explaining key messages

- Check understanding by asking the patient to confirm knowledge

- Gain feedback in order to improve the next session if necessary

- Reinforce the message in order to ensure retention.

Relevant visual aids will assist in retaining the interest of the patient:

- Demonstrations are a useful tool to tell and show techniques

- Patient involvement - active participation will allow the patient to feel included. They are more important in their oral healthcare than we are. The ideal is a partnership where we all work together.

\section{Test yourself}

1. Paralinguistics relates to:

A. patients who speak more than one language

B. the way in which people speak including voice tone and volume

\section{What percentage of} communication do we judge on non-verbal factors?
A. $7 \%$
B. $55 \%$

3. 'You don't eat cakes regularly do you?' This is:

A. a leading question

B. an open question

\section{Which of the following may make} a patient feel more comfortable?

A. talking at the same level

B. avoiding jargon 